\title{
Quantitative X-ray mapping of Au-Ag ratios in native electrum from the Fire Creek epithermal vein deposit, Lander County, Nevada (USA)
}

William Nachlas ${ }^{1}$, Luke Schranz ${ }^{2}$ and Drae Rogers ${ }^{3}$

${ }^{1}$ Department of Geoscience, University of Wisconsin-Madison, United States, ${ }^{2}$ University of NevadaReno, United States, ${ }^{3}$ University of Wisconsin-Madison, United States

Gold-Silver ratios of electrum from the Fire Creek deposit of Lander County, NV (USA), were quantified using X-ray mapping and spot analysis with EPMA (Electron Probe Microanalysis). The Fire Creek deposit produces high-grade gold and silver ore from a series of mid-Miocene high angle veins and faults hosted in basaltic-andesite along the western margin of the Northern Nevada Rift. This shallow, lowsulfidation epithermal deposit has produced about 530,000 Troy ounces of gold with average grade of $0.68 \mathrm{oz} /$ ton since underground mining commenced in 2016. The majority of gold and silver mined here occurs as electrum, naumannite, and acanthite hosted in banded and brecciated quartz \pm calcite \pm adularia \pm clay veins ranging from 0.07 to $1.83 \mathrm{~m}$ wide (Type I ore). Additional gold and silver resources hosting refractory ore have also been mined and identified. Here, ore occurs as Au and Ag in pyrite, marcasite, and arsenopyrite that are hosted in heavily clay altered rocks and fault gouge (Type II ore).

Understanding textural relationships between electrum, other $\mathrm{Au}$ - and Ag-bearing phases, and the matrix is critical for interpreting the precipitation mechanism for ore minerals within each type of deposit. Microanalytical investigation of these textures is challenging given the difficulties in sample preparation of hard minerals embedded in soft swelling clays. Samples were impregnated under vacuum using low viscosity epoxy to allow for increased penetration. Subsequent grain mounts and thin sections were ground and polished in alcohol-based fluids with final microprobe finish achieved using colloidal silica. Following sample preparation and prior to analysis, samples were stored in high vacuum chamber to promote outgassing of swelling clays prior to loading into the instrument.

Electrum crystal aggregates ranging in size from sub-micron to veins up to $\sim 5 \mathrm{~mm}$ wide within quartzadularia matrix were analyzed with a Cameca SX-Five EPMA instrument equipped with Schottky Field Emission source and five wavelength-dispersive spectrometers (WDS). A complete quantitative characterization of electrum composition was performed to determine the presence and abundance of additional elements that may occur at minor or trace concentration levels in samples from the Fire Creek deposit. Measurements were performed at multiple electron source and beam conditions, with the majority of measurements at $20 \mathrm{kV}$ accelerating voltage and 20-100 nA beam current with 1-5 $\mu \mathrm{m}$ beam diameter. Long-duration (120 s) energy dispersive X-ray spectrometry (EDS) analysis revealed only Au and Ag. Long-duration ( $>8 \mathrm{hr}$ ) WDS scans were acquired across the X-ray energy position for $\mathrm{Fe}-\mathrm{K} \alpha, \mathrm{Cu}-\mathrm{K} \alpha, \mathrm{Zn}$ $\mathrm{K} \alpha$, Se-K $\alpha$, Mo-L $\alpha$, Sb-L $\alpha, \mathrm{Hg}-\mathrm{M} \alpha$, Tl-M $\alpha, \mathrm{Pb}-\mathrm{M} \alpha$, and Bi-M $\alpha$ to search for the presence of additional impurities that have been documented to occur in electrum. Counts above the background at the $\mathrm{Cu}, \mathrm{Zn}$, $\mathrm{Se}$, and $\mathrm{Sb}$ peak positions were observed and these elements were added to the routine for quantitative WDS spot analysis.

An X-ray overlap by $\mathrm{Au}$ on the Ag position requires special attention when analyzing materials that contain elevated abundance of these elements together, such as electrum. The Ag-L $\alpha$ position on LPET diffractor is overlapped by the Au-L $\beta 5(n=4)$ high order X-ray line. This overlap is most problematic when attempting to measure low levels of Ag in materials with high levels of Au. We explored three approaches to account for this X-ray overlap. One approach is to use a conventional off-peak overlap correction as 
included in EPMA operating software programs. Another approach is to reduce accelerating voltage to below $\sim 12 \mathrm{kV}$ to prevent excitation of the Au-L series. The most effective way to prevent errant Au counts measured as Ag is to use Differential Pulse Height Analysis (PHA) to filter out high order reflections of the Au-L $\beta 5$ line at the Ag-L $\alpha$ position. Utilization of differential PHA is shown to reduce errant Au contribution to Ag measurements in electrum to below detection limits for our highest Au concentration samples.

Electrum is distributed as banding within cm-scale veins and as small masses filling vugs and cavities in quartz and adularia (Fig. 1). The distribution of electrum relative to matrix phases and the variations in $\mathrm{Au}-\mathrm{Ag}$ ratios are of primary importance in the interpretation of boiling as the principal precipitation mechanism for electrum-bearing ore at the Fire Creek deposit. Quantitative WDS mapping of $\mathrm{Au}-\mathrm{Ag}$ ratios was used to spatially evaluate compositional variability in electrum within different textures or locations in the sample. Quantification of WDS maps was performed using the Mean Atomic Number (MAN) background correction technique [1,2]. Sixteen pure element or simple compound standards ranging in Z-bar from 6-80 were selected to generate the MAN background model. Mapping of the AgL $\alpha$ (LPET) and Au-Ma (LLIF) X-ray lines was performed at $8 \mathrm{kV}$ and $200 \mathrm{nA}$ using a fully focused beam, the diameter of which was determined to be $\sim 80 \mathrm{~nm}$ from image resolution analysis [3]. Quantitative maps of $\mathrm{Si}, \mathrm{Ag}$, and $\mathrm{Au}$ (Fig. 2) reveal a relatively uniform distribution of $\mathrm{Au}-\mathrm{Ag}$ ratios ranging from 66-72 wt\% Au and 28-34 wt\% Ag, supporting a single generation of electrum precipitation. The maps reveal vugs between euhedral quartz and adularia into which the electrum precipitated. Also revealed in the Ag $\mathrm{X}$-ray maps are small grains with elevated Ag concentrations, indicating the presence of secondary grains of acanthite and/or naumannite. Quantitative WDS mapping of Au-Ag ratios in electrum provides valuable information about ore and gangue mineral forming processes within individual samples, and the fully quantified nature of WDS map data enables direct comparison between samples collected from different regions of the deposit.
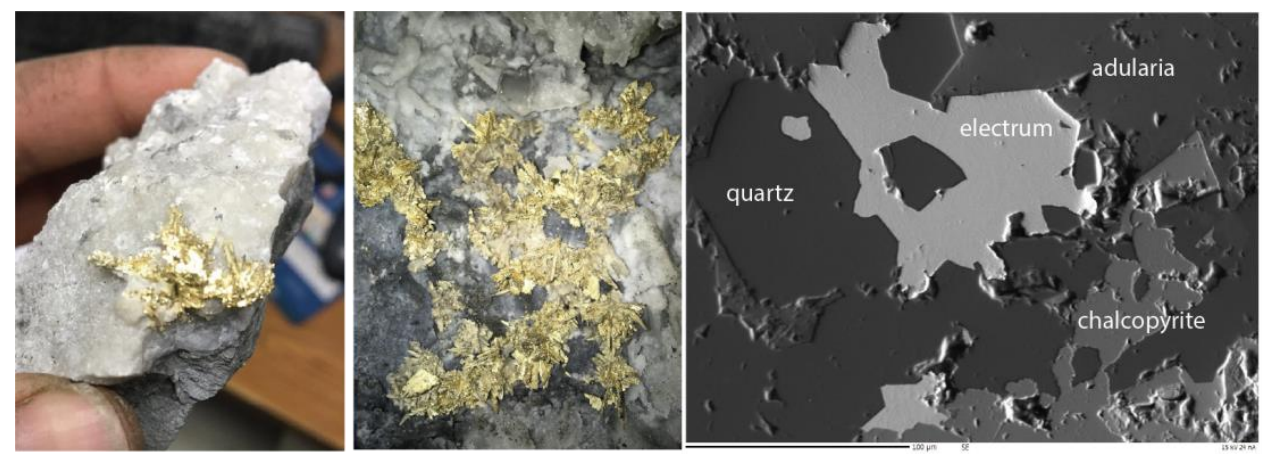

\begin{tabular}{|c|c|c|c|}
\hline $\mathrm{wt} \%$ & $\mathrm{pt} 1$ & $\mathrm{pt} 2$ & $\mathrm{pt} 3$ \\
\hline $\mathrm{Au}$ & 67.111 & 71.065 & 71.764 \\
\hline $\mathrm{Ag}$ & 31.729 & 28.643 & 28.479 \\
\hline $\mathrm{Cu}$ & 0.116 & 0.452 & 0.151 \\
\hline $\mathrm{Sb}$ & 0.113 & b.d.l. & b.d.l. \\
\hline $\mathrm{Zn}$ & 0.301 & 0.555 & 0.458 \\
\hline $\mathrm{Se}$ & 0.362 & 0.220 & 0.290 \\
\hline Total & 99.733 & 100.933 & 101.150 \\
\hline
\end{tabular}

Figure 1. Figure 1. Specimens of native electrum, BSE image of polished sample mount showing typical mineralogy, and table of representative WDS data of electrum from the Fire Creek Mine. 

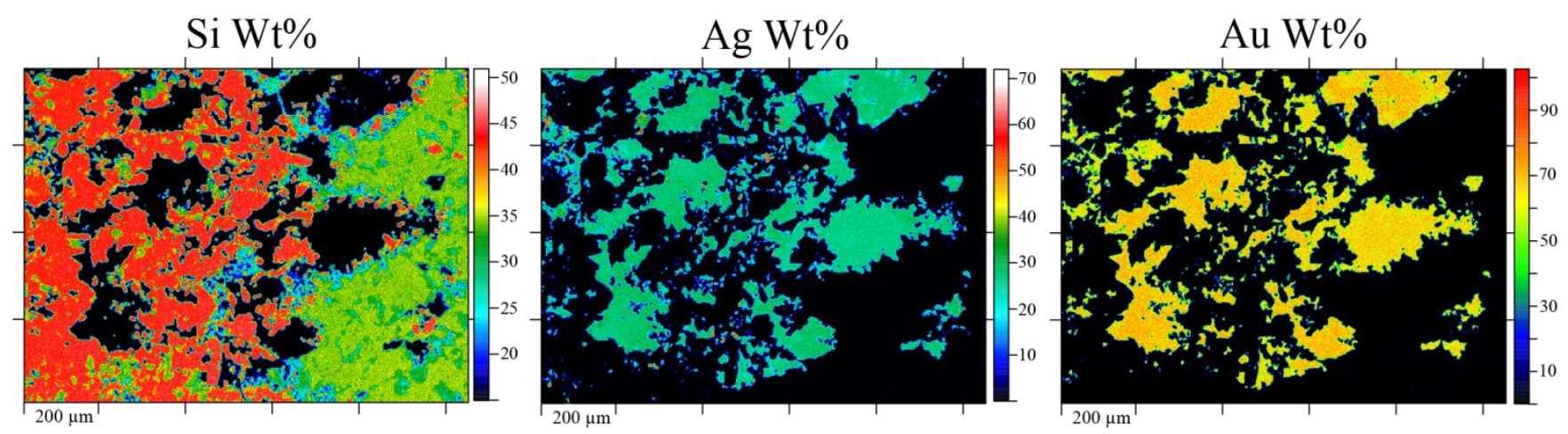

Figure 2. Figure 2. Quantitative X-ray maps of $\mathrm{Si}, \mathrm{Ag}$, and $\mathrm{Au}$ calculated in weight \% elemental using the Mean Atomic Number background model.

\section{References}

[1] Donovan, J., Allaz, J., von der Handt, A., Seward, G.G., Neill, O., Goemann, K., Chouinard, J. Carpenter, P. Quantitative WDS Compositional Mapping Using the Electron Microprobe. American Mineralogist (2021).

[2] Donovan, J., Singer, J.W., and Armstrong, J.T. A new EPMA method for fast trace element analysis in simple matrices. American Mineralogist 101.8 (2016): 1839-1853.

[3] Moy, A., Fournelle, J. Analytical Spatial Resolution in EPMA: What is it and How can it be Estimated?. Microscopy and Microanalysis 23.S1 (2017): 1098-1099. 